\author{
Military Technical College \\ Kobry El-Kobbah, \\ Cairo, Egypt.
}

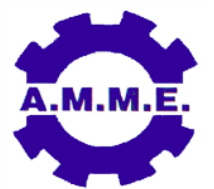

$16^{\text {th }}$ International Conference
on Applied Mechanics and
Mechanical Engineering.

\title{
AN EXPERIMENTAL STUDY OF DESICCANT WHEEL-AIR HUMIDIFIER INTEGRATION IN HOT AND DRY CLIMATES
}

\author{
M. A. Kinawy ${ }^{1}$, M. F. Cidek $^{2}$ and T. Abd-Elmalak ${ }^{3}$
}

\begin{abstract}
Desiccant dehumidification has emerged as an alternative or as a supplement to conventional vapor compression systems for cooling and conditioning air in commercial and industrial buildings to remove the latent heat load. The advantages of desiccant-based air conditioning systems, compared to conventional ones based on the dehumidification by cooling, have been highlighted in many research papers. The energy saving and the reduction of the environmental impact are higher when the desiccant material is regenerated by using "free" thermal energy.

We study performance of air humidifier cooler systems with a rotary desiccant wheel, as the heat and moisture transfer medium in hot and dry climates as an alternative to vapor compression cooling. The wheel is symmetrically balanced and is operated with counter-flow pattern. This investigation examines the effect of operating conditions and different design parameters of desiccant wheel with air humidifier cooler such as: the regeneration temperature, regeneration air mass flow rate, desiccant wheel rotational speed, silica gel quantity (porosity), concentration of calcium chloride solution (mass\%), and the concentration of sodium chloride solution (mass\%). Air humidifier cooler and desiccant wheel are conducted on a lab-scale unit. Test rig consists of a main unit and accessories were carried out in the laboratories of Faculty of Energy Engineering, Aswan University.
\end{abstract}

\section{KEY WORDS}

Experimental work; Desiccant rotary wheel; Absorption and regeneration, Evaporative system.

1 Administrator, Dept. of Mechanical Power, Faculty of Energy Eng., Aswan Univ., Egypt.

2 Assistant professor, Dept. of Mech. Power, Faculty of Energy Eng., Aswan Univ., Egypt.

3 Associate professor, Dept. of Mech. Power, Faculty of Energy Eng., Aswan Univ., Egypt. 


\section{NOMENCLATURE}

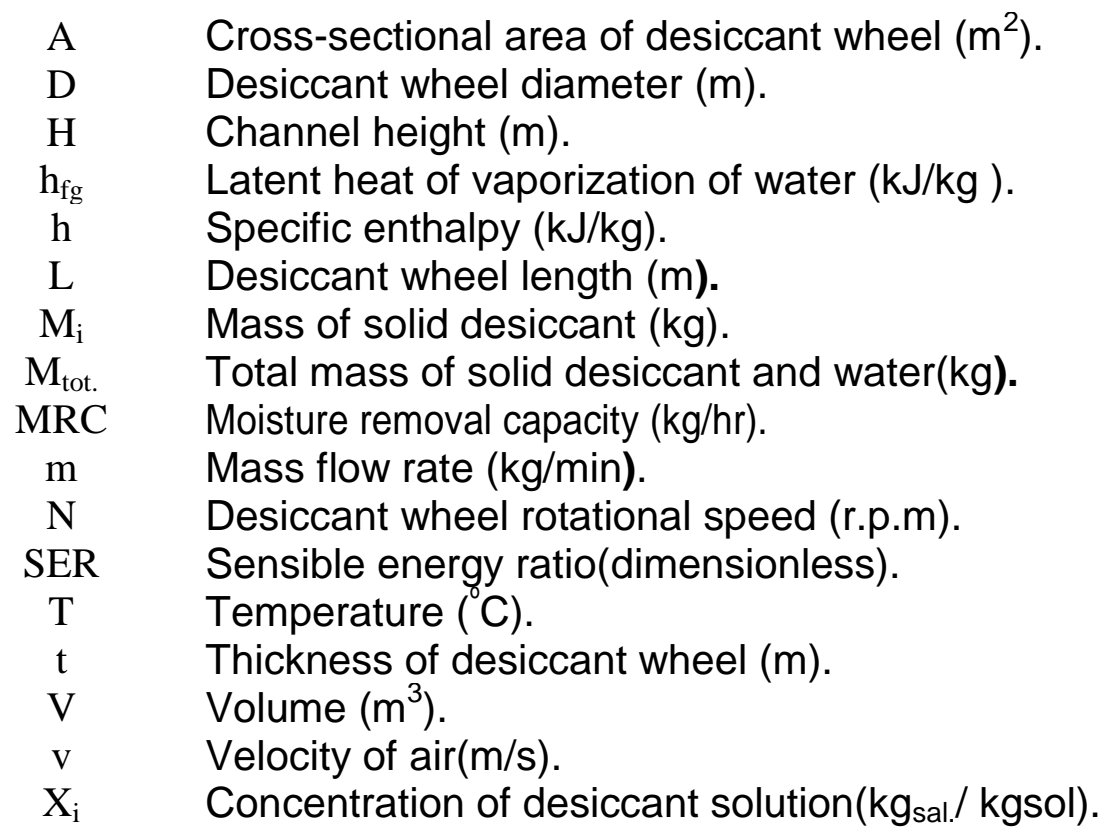

\section{Greek Symbols}

$\eta_{\mathrm{h}} \quad$ Enthalpy efficiency (\%).

$\eta_{\mathrm{T}} \quad$ Temperature efficiency (\%).

$\rho_{\mathrm{a}} \quad$ Air density $\left(\mathrm{kg} / \mathrm{m}^{3}\right)$.

$\rho_{\mathrm{d}} \quad$ Silica gel density $\left(\mathrm{kg} / \mathrm{m}^{3}\right)$.

$\tau \quad$ Time (min.).

$\varphi \quad$ Relative humidity (\%).

$\psi_{\mathrm{ab}} \quad$ Dehumidification effectiveness (\%)

$\psi_{\text {reg }} \quad$ Regeneration effectiveness (\%)

$\omega \quad$ Air humidity ratio $\left(\mathrm{kg}_{\mathrm{w}} / \mathrm{kg}_{\text {air }}\right)$.

\section{Subscripts}

DCOP Dehumidification coefficient of performance (dimensionless).

proc Process air.

Reg Regeneration air.

1,2 Dehumidification inlet and outlet states or Deh. and product respectively.

3,4 Regeneration inlet and outlet states, or regeneration and exhaust respectively.

\section{INTRODUCTION}

Desiccants are chemicals with great affinity to moisture. Therefore, desiccants can be used as supplement to conventional vapor compression systems in order to remove the latent heat load. Desiccants are efficient in handling latent heat load (i.e., reducing the humidity), but the evaporator in the vapor compression system is efficient in handling the sensible cooling loads (i.e., lowering the air temperature). Kabeel [1] summarized the advantages of using desiccants in the following points: 
(1) It consumes very little electrical energy, and for regeneration process, it allows the use of solar energy and waste energy.

(2) It is efficient when latent heat load is larger than the sensible load.

(3) It is a clean technology, which can be used to condition the internal environment of buildings and operates without the use of harmful refrigerants.

(4) The achieved control of humidity is better than that when using vapor compression systems.

(5) In some cases, the cost of energy to regenerate the desiccant is less than that when compared with the cost of energy to dehumidify the air by cooling it below its dew point.

(6) Improvement in indoor air quality is more likely due to the normally high ventilation.

(7) It has the capability of removing airborne pollutants.

Kabeel [1] studied a solar powered air conditioning system using liquid desiccant. The effect of airflow rate and solar radiation intensity on the system regeneration and absorption processes was studied. Also empirical equation for wheel effectiveness as a function of airflow rate for regeneration and absorption process was obtained. Ahmed et al. [2] studied evaluation and optimization of a solar desiccant wheel performance. Results showed that there was a maximum value of each design parameter at each operating condition. Further, an efficient wheel performance requires an effective range between 1 and $5 \mathrm{~kg} / \mathrm{min}$ of airflow rate.

Giovanni et al. [3] have carried out experimental analyses on the dehumidification and thermal performance of a desiccant wheel. The desiccant material was regenerated by means of low-temperature thermal energy (abut $65^{\circ} \mathrm{C}$ ) from a microcogenerator. Hamed et al. [4] have carried out theoretical and experimental evaluation of the effect of bed configuration and operating conditions on the performance of desiccant dehumidification system. An experimental analysis was presented on the performances of a silica-gel desiccant wheel by Angrisani et al. [5], inserted in a test facility characterized by an advanced desiccant air handling unit, coupled to an electric chiller, a natural gas-fired boiler and a small scale cogenerator. Desiccant wheel operation has been investigated by experimental study by Mandegari and Pahlavanzadeh [6]. Experimental conditions included different climates (hot dry and hot humid) at different operating parameters (regeneration temperature and wheel speed). Due to the temperature and humidity measurements of inlet and outlet streams, the desiccant wheel efficiency in each definition was calculated.

Ruivo et al. [7] presented experimental published in the literature of the global behavior of desiccant wheels for different inlet states of the process and regeneration airflows and for different rotation, speeds were used to investigate a new pair of independent effectiveness parameters and to derive correlations for their estimation. Antonellis et al. [8] investigated desiccant wheels performance and optimization. The analysis was carried out through a one-dimensional gas side resistance model that considered developing temperature and velocity profiles along the channels. A mathematical model for predicting the performance of novel silica gel haloids compound desiccant wheel was established by Wang et al. [9]. Both the gas side resistance and the solid side resistance were considered in the model. Kabeel [10] theoretically and experimentally studied the effect of design and 
operating parameters on the performance of a multilayer desiccant packed bed. Panarasa and Kyriakisb [11] presented an experimental validation of a simplified approach for a desiccant wheel model.

\section{EXPERIMENTAL SETUP}

The aim of the experimental work is to study the performance of air humidifier cooler system with a rotary desiccant wheel in hot and dry climates. For this reason, an experimental system has been designed and built. The main parts of the test setup are shown in the schematic diagram in Fig. 1. A photograph of the system used is shown in Fig. 2. The system consists of following parts:

(a) Air humidifier conditioning,

(b) Rotary desiccant wheel,

(c) Blower and electric heater, and

(d) Electrical D.C motor.

\section{Air Humidifier Conditioning:}

Waleed and Soubhi [12] presented an equation capable of accurately calculate the wet bulb temperature from the ambient temperature and relative humidity. Equations for calculation of the outlet air temperature and relative humidity in the direct evaporative cooler were also presented. Specification of this work desert air conditioning is as follows:

Type: Al jazirah for home appliances co. Itd. (jaz. 13110)

Motor power: (1/3 HP) flow rate: $19 \mathrm{~L} / \mathrm{h}$

The maximum permissible inlet water pressure: $300 \mathrm{kPa}$

\section{Rotary Desiccant Wheel}

The rotary desiccant wheel is made of galvanized iron of $0.28 \mathrm{~m}$ diameter and $0.35 \mathrm{~m}$ length. It is divided into two parts. The first part is the regeneration part that equals $50 \%$ of the total surface area. The second part is the absorption part that equals $50 \%$ of the total surface area. The two parts are separated carefully as shown in Fig.3

\section{Blower and Electric Heater}

The regeneration air is supplied by means of individual blower through .75 $\mathrm{m}$ long calming sections and can be adjusted to desired flow rates using gate at the blower inlet. The air used for regeneration purpose is preheated up to the desired temperature by an electric heater of $2 \mathrm{~kW}$ capacity and thermostat are used to keep the regeneration temperature of the exit air from the blower at the required value.

\section{Electrical D.C Motor}

Rotary D.C motor 19V, 133 r.p.m is used to drive the desiccant wheel at variable speed to alternate the position of the absorption and the regeneration areas by using voltage control as shown in Fig. 1. 


\section{Measuring Devices}

Different parameters are measured in this work; these include;

1- Inlet and outlet temperatures for both regeneration and absorption air.

2- Ambient air dry-bulb and wet-bulb temperatures.

3- Inlet and outlet relative humidities for both regeneration and absorption air.

4- Air velocity and the rotating speed of D.C motor.

Inlet and outlet temperatures and relative humidity of regeneration and adsorption air are measured using TENMARS [Temperature / Humidity Meter] TM-183.

The accuracy of the device for relative humidity \pm 2.5 percentage for $30-80 \%$ and for temperature $\pm 0.8^{\circ} \mathrm{C}, \pm 1.5^{\circ} \mathrm{F}$. The velocity of the air is measured using a digital anemometer type TENMARS [Air velocity Meter] TM-402 with an accuracy of $( \pm 2 \%+0.2) \mathrm{m} / \mathrm{s}$, and the measuring range of $0.2-25 \mathrm{~m} / \mathrm{s}$ with resolution of $0.1 \mathrm{~m} / \mathrm{s}$. The rotating speeds of the desiccant wheel are measured by stopwatch.

\section{System Operation}

There are two air paths in the tested system as shown in Fig.1. In the first path, the air exits from the air blower then heater at a high temperature and flows through the regeneration part in order to regenerate the moisture from the solution or silica gel. This increases the solution concentration (relative humidity) on the desiccant after a specific time. In the other air path, the moist airflows from desert air conditioning through the absorption part to absorb the moisture from it. This will decrease the concentration of the solution (relative humidity) on the desiccant after a certain time. The air performs two processes simultaneously in the system, namely the dehumidification process and the regeneration process.

\section{Dehumidification process}

The temperature humidity processes of the system during absorption are shown in Fig.4. At point 1 (feed), the ambient air is low temperature and high relative humidity. By passing the air through the desiccant bed in the rotary wheel, the relative humidity is decreased but the temperature increases in the process air at point 2 (product).

\section{Regeneration process}

The outside air enters to the air blower and is then heated to point 3 (Reg.). The ambient air is at high temperature and low relative humidity. Then the heated air passes to the desiccant bed in the rotating wheel in which the relative humidity will be increased and the temperature decreased at point 4 (exhaust).

\section{PERFORMANCE PARAMETERS}

In order to evaluate the performance of the desiccant wheel with air humidifier cooler, the performance parameters described herein have been analyzed: 
(1) The dehumidification effectiveness, $\Psi_{\mathrm{ab}}$, represents the ratio between the real and the ideal dehumidification capability of the desiccant wheel, Kabeel [1]:

$$
\psi_{a b}=\frac{\omega_{1}-\omega_{2}}{\omega_{1}-\omega_{2 i d e a l}}
$$

where $\omega_{\text {2ideal, }}$ is the ideal-specific humidity of the desiccant wheel. Assuming the air is completely dehumidified at this point, the value of $\omega_{\text {2ideal }}$ can be considered zero.

(2) The regeneration effectiveness, $\Psi_{\text {reg }}$, represents the ratio of the change in the air humidity in the regeneration process to the inlet humidity, Kabeel [1]:

$$
\psi_{\text {reg }}=\frac{\omega_{4}-\omega_{3}}{\omega_{3}} .
$$

(3) The effectiveness parameter based on the temperature changes, also known as temperature efficiency (thermal effectiveness), is defined as, Ruivo et al. [7]:

$$
\eta_{T}=\frac{T_{1}-T_{2}}{T_{1}-T_{3}}
$$

(4) The effectiveness parameter based on the changes of the specific enthalpy $h$, also known as enthalpy efficiency (enthalpy effectiveness), is defined as, Ruivo et al.[13]:

$$
\eta_{h}=\frac{h_{1}-h_{2}}{h_{1}-h_{3}}
$$

(5) The Moisture Removal Capacity, MRC, is defined as, Ali and Pahlavanzadeh [6]:

$$
M R C=\dot{m}_{1}\left(\omega_{1}-\omega_{2}\right)
$$

In case of unbalanced flow, i.e. different area of process and regeneration section $\mathrm{MRC}$ is more appropriate than effectiveness that is widely used as performance index, Jae et al. [14].

(6) The Dehumidification Coefficient of Performance, DCOP, represents the ratio between the thermal power related to the air dehumidification and the thermal power supplied for the regeneration process, Wang et al. [9]:

$$
D C O P=\frac{\dot{m}_{1} h_{f g}\left(\omega_{1}-\omega_{2}\right)}{\dot{m}_{2}\left(h_{3}-h_{a m b .}\right)}=\frac{\dot{Q}_{\text {Latent }}}{\dot{Q}_{\text {Re generation }}}
$$

The latent heat of vaporization of water, $h_{\mathrm{fg}}$, has been evaluated by means of the following empirical cubic function, Giovanni et al. [3]:

$$
\mathrm{h}_{\mathrm{fg}}=-0.614342 * 10^{-4} \mathrm{~T}_{1}{ }^{3}+0.158927 * 10^{-2} \mathrm{~T}_{1}{ }^{2}-0.236418 * 10 \mathrm{~T}_{1}+0.250079 * 10^{4}
$$


(7) The sensible energy ratio, SER, represents the ratio between the thermal power related to the air heating through the wheel on the process side and the thermal power supplied for the regeneration process, Giovanni et al. [3]:

$$
S E R=\frac{\dot{m}_{1}\left(h_{2}-h_{1}\right)}{\dot{m}_{2}\left(h_{3}-h_{1}\right)}
$$

In this work, the performance parameters described in this section ( $\psi_{\mathrm{ab}}, \psi_{\mathrm{reg}}, \eta_{\mathrm{T}}, \eta_{\mathrm{h}}$, MRC, DCOP, and SER) are obtained by calculation from measured variables (temperature, relative humidity and velocity of the air).

Mass flow rate of process air $\left(m_{1}\right)$ and mass flow rate of regeneration air $\left(m_{2}\right)$ are calculated by measuring the velocity of the air and are defined as:

$$
\begin{gathered}
\dot{m}_{1}=\rho_{1} A_{1} v_{1} \\
\dot{m}_{2}=\rho_{2} A_{2} v_{2}
\end{gathered}
$$

\section{EXPERIMENTAL RESULTS}

The aim of the experimental work is to study the performance of a desiccant air conditioning system that uses air humidifier cooler and a rotary desiccant wheel as the heat and moisture transfer medium in hot and dry climates. The results were obtained at different operating conditions and different design parameters.

\section{Study of Silica Gel}

First run experimental silica gel is applied as the working solid desiccant in this work with different quantity of mass compared with maximum mass within the wheel. Changes of the regeneration air temperature; the rotational speed of desiccant wheel and the regeneration air mass flow rate are investigated.

\section{Effect of regeneration air temperature on the outlet temperatures, adsorption and regeneration relative humidity}

Figure 5(a) shows the change of outlet temperatures of adsorption airflow with time, and Fig. 5(b) shows the change of the outlet relative humidity of adsorption airflow with time. These figures are based on the same quantity mass of silica gel, $5 \mathrm{~kg}$, $(65 \%)$ also the same rotating speed of desiccant wheel (1 r.p.m) and different $T_{\text {Reg.. }}$

As the regeneration temperature increased, the adsorption capacity decreases, Ahmed et al. [4], where more water is removed and the vapor pressure on the bed surface decreases resulting in the best performance of air humidifier.

\section{Effect of regeneration air temperature on the performance parameters}

The parametric analysis of regeneration inlet conditions is shown in Figures 6 . Moreover, the obtained results can be explained in the following way: low 
regeneration air temperature leads to higher relative humidity and consequently to higher capacity of desiccant material of keeping water. As known, by increasing the regeneration temperature, dehumidification improves because of the better performance of desorption process as shown in the figures. The enthalpy efficiency, temperature efficiency, dehumidification effectiveness, regeneration effectiveness and MRC increases with increasing the regeneration temperature due to higher mass transfer between the wet air and the adsorbent layer. As regards, DCOP and SER (Fig. 6c) the increase in the dehumidification capability with regeneration temperature does not balance the rise in the specific regeneration thermal power $\left(\mathrm{h}_{3}\right.$ $h_{a m b}$ ), so DCOP decreases. The increased heating of the desiccant wheel on the regeneration side and, because of the rotation of the wheel, on the process side; but the increase in regeneration temperature itself causes an overall reduction of sensible energy ratio (SER) as expected based on Eq. (8) Giovanni et al. [3].

\section{Effect of rotational speed of desiccant wheel on the outlet temperatures, adsorption and regeneration relative humidity}

Figure 7(a). Shows the variation of the outlet temperatures of adsorption air flow with time. Fig.7 (b) shows the change of the outlet relative humidity of adsorption air flow with time. These figures depend on the same quantity of silica gel $5 \mathrm{~kg}(65 \%)$ but different rotating speed of desiccant wheel, and same regeneration temperature, 150 $\stackrel{\circ}{\circ}$.

From these figures, it was observed that as the rotational speed of desiccant wheel is lowered the best performance of air humidifier and the adsorption temperature should be increased.

\section{Effect of rotational speed of desiccant wheel on the performance parameters}

For considering the effect of desiccant wheel rotational speed on its operation, all the other parameters have been fixed and the speed was set to be the only independent variable, Fig.8, and the variation of efficiencies versus the wheel speed has been evaluated. As it can be seen with increasing the desiccant wheel speed, heat is carried from the regeneration side to the process side thus the dehumidification efficiency improves due to the smaller time intervals for the humidification and dehumidification. Other efficiencies also have the same trends like dehumidification, Ali and Pahlavanzadeh [6]. However, at higher (r.p.m) the amount of water absorbed is nearly equal to the amount of water desorbed. If lower (r.p.m) is used the regeneration temperature should increase. As a result, there must be an optimal rotation speed under different conditions to have the best dehumidification capacity. Under the condition of different rotation speed, DCOP is determined by MRC only and then it has the same trend as MRC as shown in Fig. 8(c) and Fig. 8(d) Wang et al.[9]. SER obtains a flat maximum value when the (r.p.m) about 1.5r.p.m due to the fact that amount of water absorbed is nearly equal to the amount of water desorbed.

\section{Effect of the quantity of silica gel on the outlet temperatures and adsorption, regeneration relative humidity}

Figure 9(a). Shows the change of outlet temperatures of adsorption air flow with time, and Fig. 9(b) shows change of the outlet relative humidity of adsorption air flow 
with time. It can observed that the quantity of mass of the silica gel is the best when the mass in the bed equals $5 \mathrm{~kg}(65 \%)$, where the best performance of air humidifier , the higher amount of water absorbed/desorbed in the cycle thus the relative humidity of adsorption air is lowered. As the quantity of the silica gel increased above $6 \mathrm{~kg}$ $(80 \%)$ this leads to higher pressure drops in the desiccant wheel because of high turbulence of fluid flow through it. The optimum length of the bed can be recommended from the experimental results according to the operation time, Kabeel [10].

\section{Effect of the quantity of silica gel on the performance parameters}

For considering the effect of the quantity of silica gel on its operation, all the other parameters have been fixed and the quantity was set to be the only independent variable. In Fig 10 (a), the temperature efficiency increases with increasing the quantity of silica gel, while the enthalpy efficiency decreases to quantity of $5 \mathrm{~kg}$ then increases with increasing the quantity of silica gel. From Fig. 10(b) it is found that the dehumidification effectiveness and regeneration effectiveness are nearly equal (about $6.5 \%$ ) at quantity $5 \mathrm{~kg}$ where equilibrium is reached ,i.e., the amount of water absorbed is nearly equal to the amount of water desorbed thus the outlet relative humidity of adsorption air and outlet process air temperature are lowered. In Fig.10(c),MRC increases with increasing the quantity of the silica gel to maximum value at $5 \mathrm{~kg}$ then decreases with increasing the quantity of silica gel. DCOP and SER obtain a flat maximum value when the quantity of silica gel is about $5 \mathrm{~kg}$, Fig. 10 (d).

\section{Effect of the regeneration air mass flow rate on the performance parameters}

In Figure 11, the influence of the parameter of the regeneration air mass flow rate is analyzed: the process airflow rate is kept constant, while varying the regeneration airflow rate. Figure 11(a) shows that the enthalpy efficiency and temperature efficiency increased with increasing the regeneration mass flow rate. Similar consideration can be made with reference to Fig. 11(b) and Fig. 11(c) showing that the dehumidification effectiveness and MRC increase with regeneration mass flow rate from $2 \mathrm{~kg} / \mathrm{min}$ to $2.5 \mathrm{~kg} / \mathrm{min}$. In fact, the increase in mass flow rate, with a fixed regeneration temperature, determines a rise in the available regeneration thermal power, so the desiccant material in the regeneration side is subjected to a deeper drying process, Giovanni et al. [3]. With a low regeneration air mass flow rate (from $1 \mathrm{~kg} / \mathrm{min}$ to $2 \mathrm{~kg} / \mathrm{min}$ ), a reduction in MRC and dehumidification effectiveness occurs. From Fig. 11(d), on the other hand the increase of mass flow rate causes a proportional rise in regeneration thermal power, so DCOP reduces. The fall of SER determines a rise in the water vapor adsorbed by the silica gel, therefore an increase in the adsorption heat and of the outlet process air $\left(\mathrm{T}_{2}\right)$, Wange et al. [9].

\section{Comparison between the Effect of Silica Gel, Calcium Chloride and Sodium Chloride on the Performance Parameters}

A comparison was done between the best results obtained at different mass percent of silica gel, calcium chloride solution, and sodium chloride solution on the performance parameters based on the same conditions ( $N=1$ r.p. $\left.m, T_{\text {Reg. }}=150 \stackrel{\circ}{\circ} \mathrm{C}\right)$. The system is effective when using calcium chloride solution (33\%mass) compared 
to silica gel and sodium chloride solution where the regeneration temperature of the calcium chloride is less than that required for silica gel thus it is attractive for a number of waste heat and solar thermal applications and also lower the humidity of dehumidified air exiting the desiccant wheel as shown in Fig. 12, thereby increasing the efficiency of the desiccant cooling process and also increasing the rate of dehumidification while reducing desiccant wheel size and cost. This would be achieved with minimum pressure drop over the axial length of the desiccant wheel, Stefano et al.[8].

\section{CONCLUSIONS}

Based on the experimental results obtained for different quantities of silica gel, calcium chloride solution and sodium chloride solution as the working desiccant material, the salient features of the present work are summarized as follows:

1) For the specified design conditions, the quantity mass of silica gel used in present work $5 \mathrm{~kg}(65 \%$ by mass $)$ is suitable one, at which equilibrium occurs (i.e. the amount of water absorbed is nearly equal to the amount of water desorbed).

2) Control of the rotation speed of D.C motor that rotates the desiccant wheel is about 1r.p.m to bring out the best performance in a rotary adsorptive dehumidifier itself and in the air humidifier cooling process.

3) The Psychrometric properties of the process air entering the wheel (outlet from air humidifier cooler) and the regeneration temperature (about $127^{\circ} \mathrm{C}$ ) strongly influence the performance of the desiccant wheel.

4) When the ratio between the regeneration and process air flow rates rises, in the case of fixed regeneration temperature, the dehumidification effectiveness increases, as well as the Moisture Removal Capacity (MRC)

5) A higher DCOP indicates a better system performance because the energy input to the regeneration air is utilized in a better way or less heat is being used to heat up the desiccant wheel. It is observed from the comparison between the desiccant materials that the sodium chloride solution has a higher DCOP indicating less heat used to heat up the desiccant wheel.

6) Decreasing the desiccant wheel rotational speed caused smaller time intervals between adsorption and desorption processes, hence all of efficiencies were improved. The relative humidity exit from the process air is improved.

7) The system is highly effective in the regeneration process for all flow rates compared with the absorption process.

\section{REFERENCES}

[1] Kabeel A.E. ," Solar powered air conditioning system using rotary honeycomb desiccant wheel", Renewable Energy 32 (2007) 1842-1857.

[2] Ahmed M.H., Kattab N.M., Fouad M.," Evaluation and optimization of solar desiccant wheel performance", Renewable Energy 30 (2005) 305-325.

[3] Giovanni Angrisani, Francesco Minichiello, Carlo Roselli, Maurizio Sasso, "Experimental analysis on the dehumidification and thermal performance of a desiccant wheel", Applied Energy 92 (2012) 563-572. 
[4] Ahmed M. Hamed, Khalil A., Kabeel A.E., Bassuoni M.M., Elzahaby A.M., "Performance analysis of dehumidification rotating wheel using liquid desiccant", Renewable Energy 30 (2005) 1689-1712.

[5] Giovanni Angrisani, Alfonso Capozzoli, Francesco Minichiello, Carlo Roselli, Maurizio Sasso," Desiccant wheel regenerated by thermal energy from a microcogenerator: Experimental assessment of the performances", Applied Energy 88 (2011) 1354-1365.

[6] Ali Mandegari M., Pahlavanzadeh H. ,"Introduction of a new definition for effectiveness of desiccant wheels", Energy 34 (2009) 797-803.

[7] Ruivo C.R., Costa J.J., Figueiredo A.R., Kodama A.,"Effectiveness parameters for the prediction of the global performance of desiccant wheels An assessment based on experimental data ", Renewable Energy 38 (2012) 181187.

[8] Stefano De Antonellis, Cesare Maria Joppolo, Luca Molinaroli," Simulation, performance analysis and optimization of desiccant wheels", Energy and Buildings 42 (2010) 1386-1393.

[9] Wang R.Z., Ge T.S., Ziegler F. r, "A mathematical model for predicting the performance of a compound desiccant wheel (A model of compound desiccant wheel)", Applied Thermal Engineering 30 (2010) 1005-1015.

[10] Kabeel A.E.," Adsorption-desorption operations of multilayer desiccant packed bed for dehumidification applications", Renewable Energy 34 (2009) 255-265.

[11] Panarasa G.Mathioulakisa, Belessiotis V. Kyriakisb," Experimental validation of a simplified approach for a desiccant wheel model," Energy and Buildings 42 (2010) 1719-1725.

[12] Waleed A. Abdel-Fadeel, Soubhi A. Hassanein, "Calculations of the outlet air conditions in the direct evaporative cooler", Journal of Engineering Sciences, Assiut University,Vol.40,No.5 ,September(2012) 1351-1358.

[13] Ruivo C.R. , Carrillo-Andrés A., Costa J.J.. Domínguez-Muñoz," A new approach to the effectiveness method for the simulation of desiccant wheels with variable inlet states and airflows rates ", Applied Thermal Engineering (2012) 1-9.

[14] Jae Dong Chunga, Dae-Young .Leeb,"Effect of desiccant isotherm on the performance of desiccant wheel", international journal of refrigeration 32 (2009)720-726.

[15] Stephen D. White, Mark Goldsworthy, Roger Reece, Thorsten Spillmann, Abdullah Gorur, Dae-Young Lee," Characterization of desiccant wheels with alternative materials at low regeneration temperatures", international journal of refrigeration 34(2011) 1786-1791.

[16] Wang R.Z., Ge T.S., Li Y., Dai Y.J. ," A review of the mathematical models for predicting rotary desiccant wheel" , Renewable and Sustainable Energy Reviews 12 (2008) 1485-1528. 


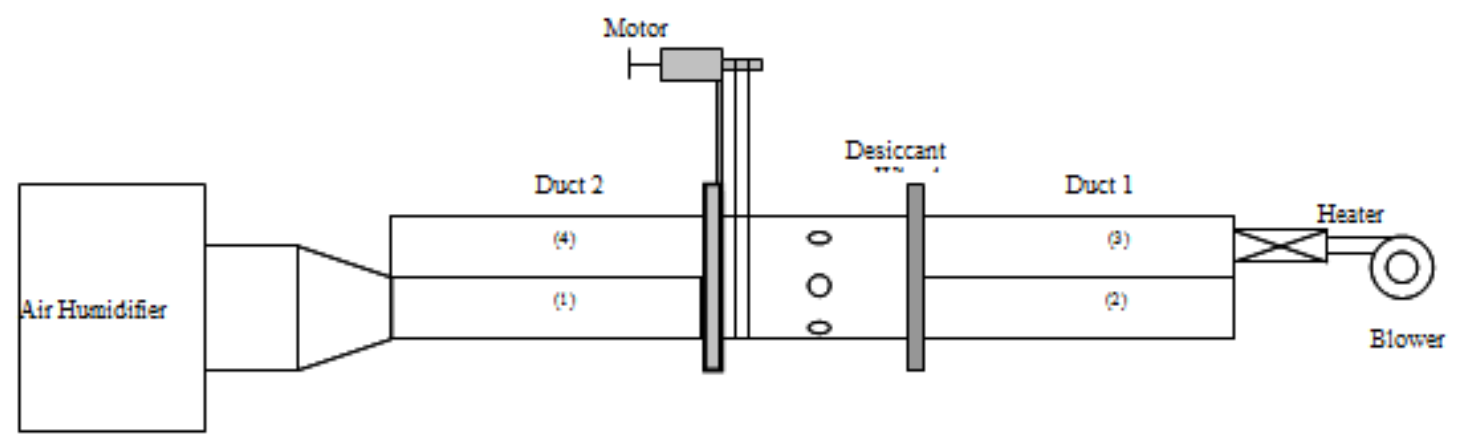

Fig.1. Schematic diagram of rig configuration.

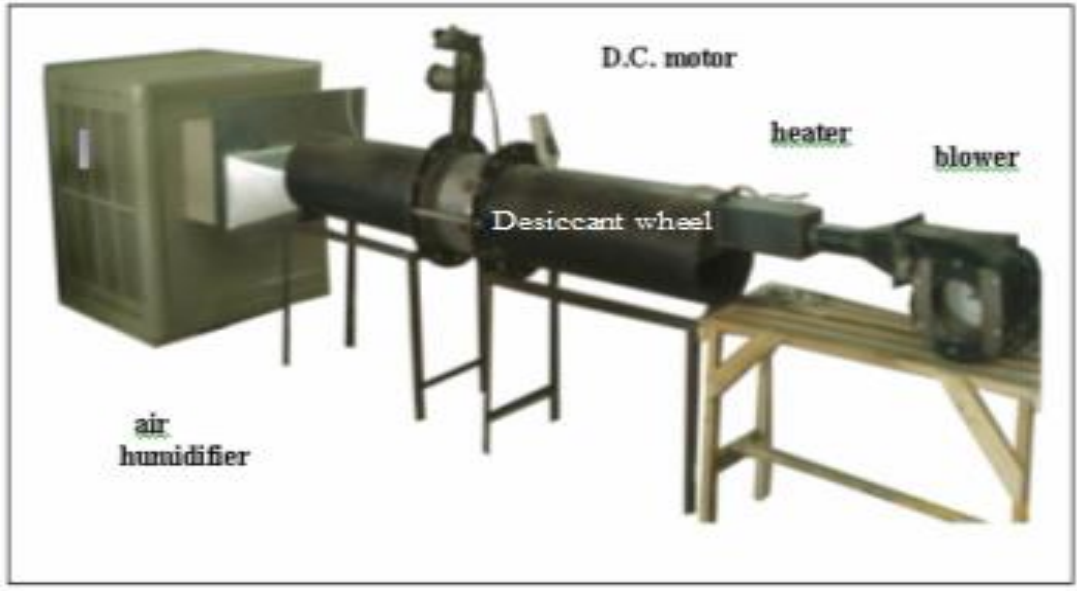

Fig.2. Test rig photograph.

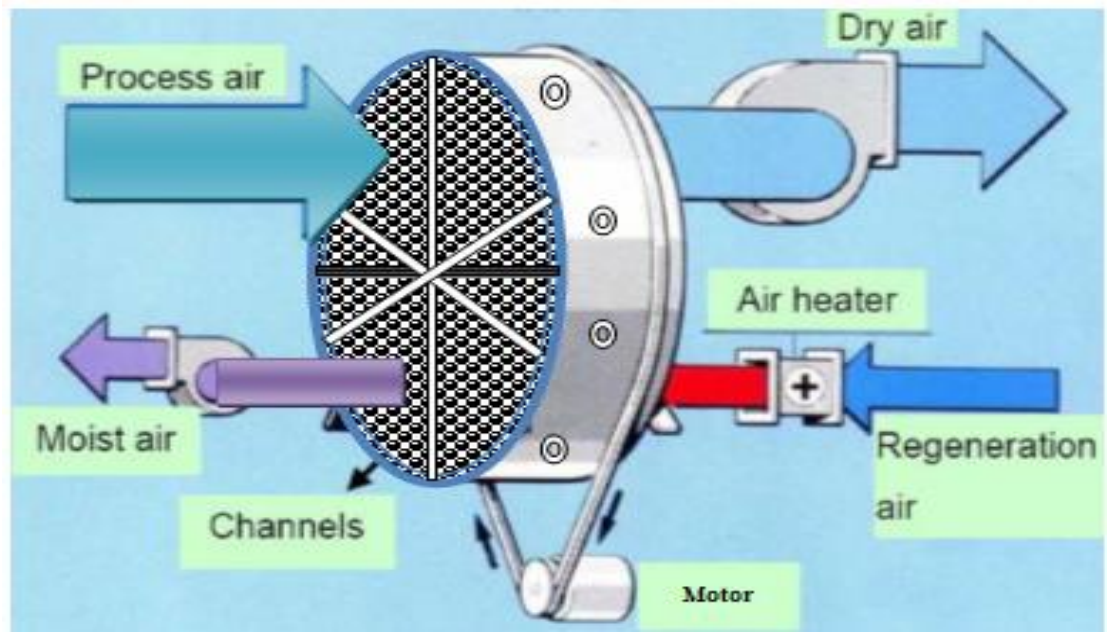

Fig.3. Schematic diagram of desiccant wheel. 


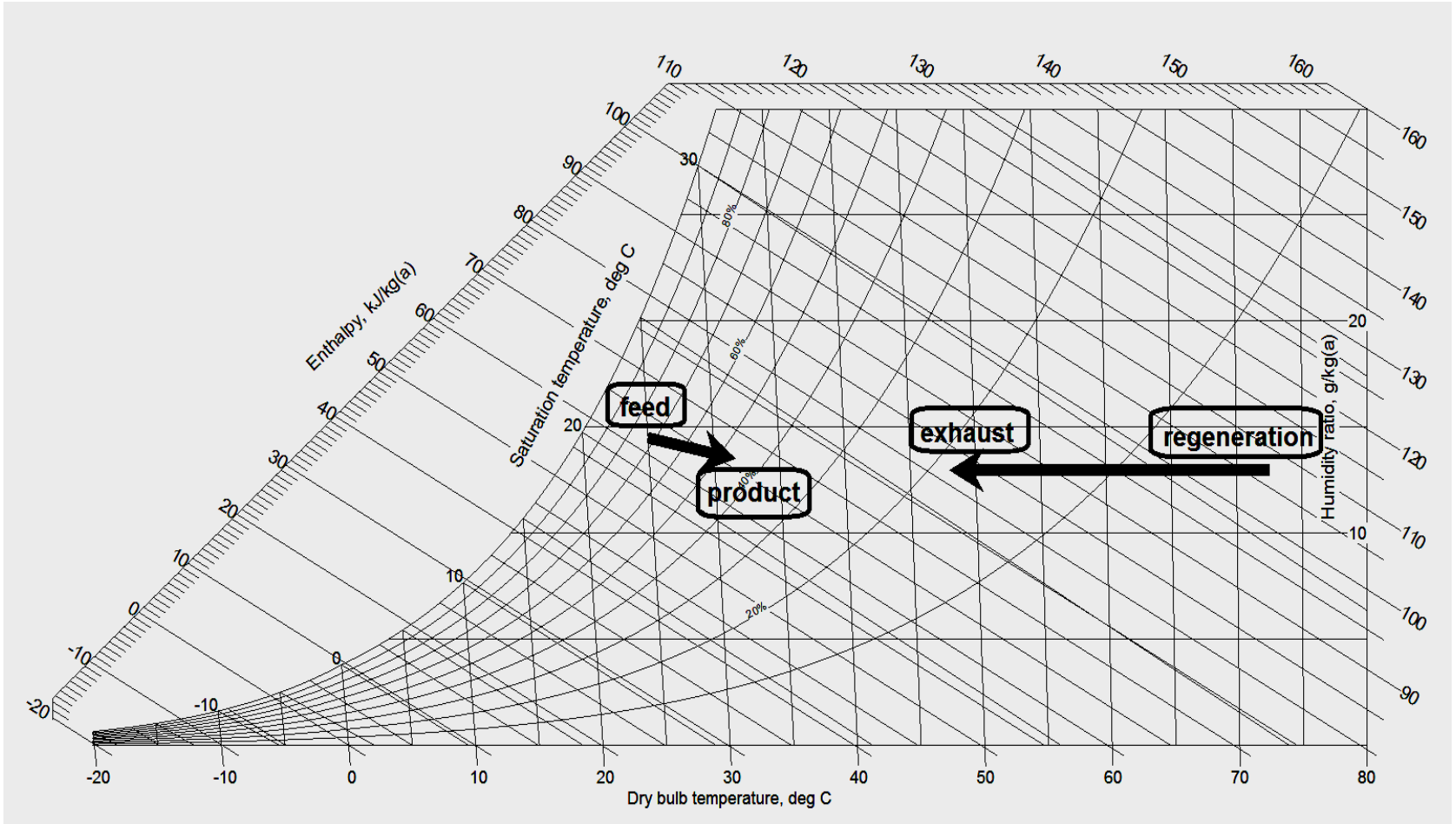

Fig.4. Psychometric chart of system processes.

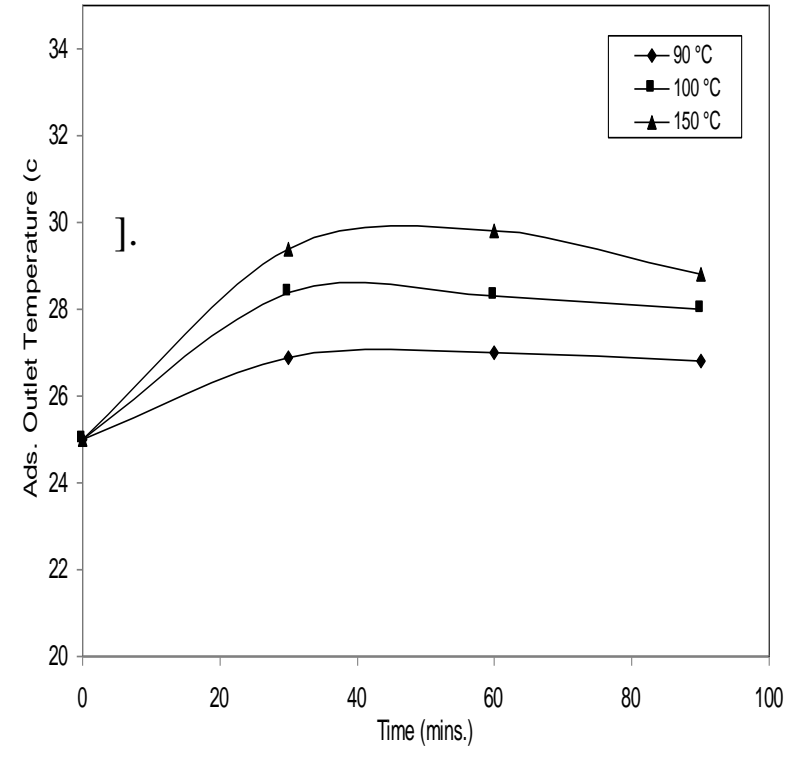

(a)

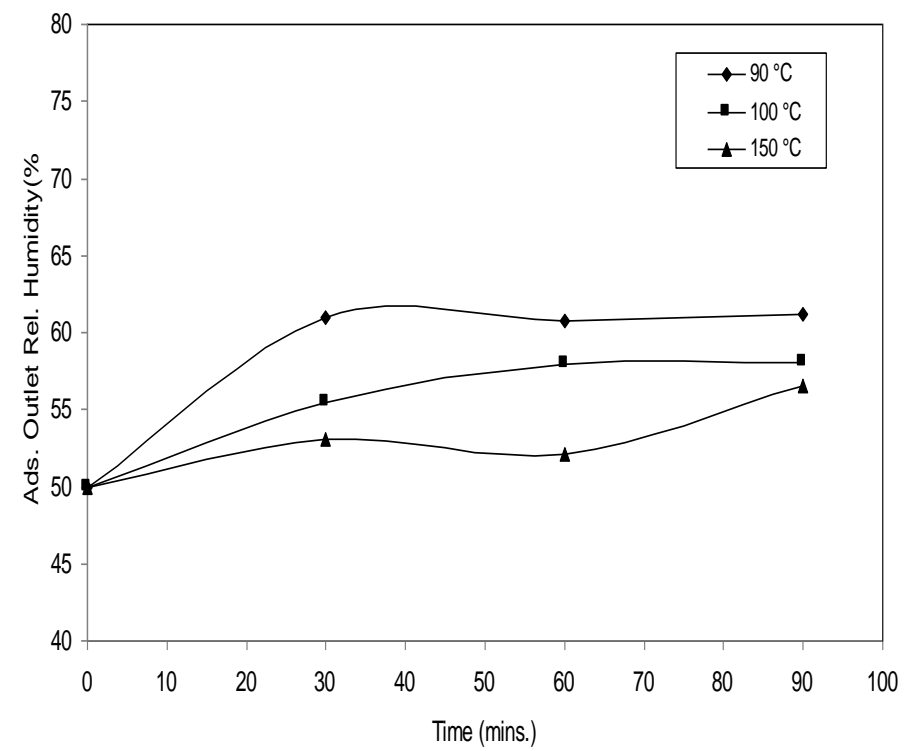

(b)

Fig. 5. The relation between (a) the exit ads. temperature (b) the exit ads. relative

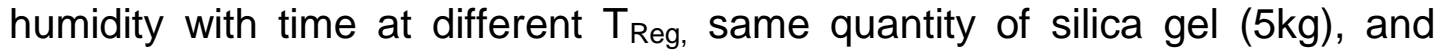
speed of Desiccant wheel (1 r.p.m). 


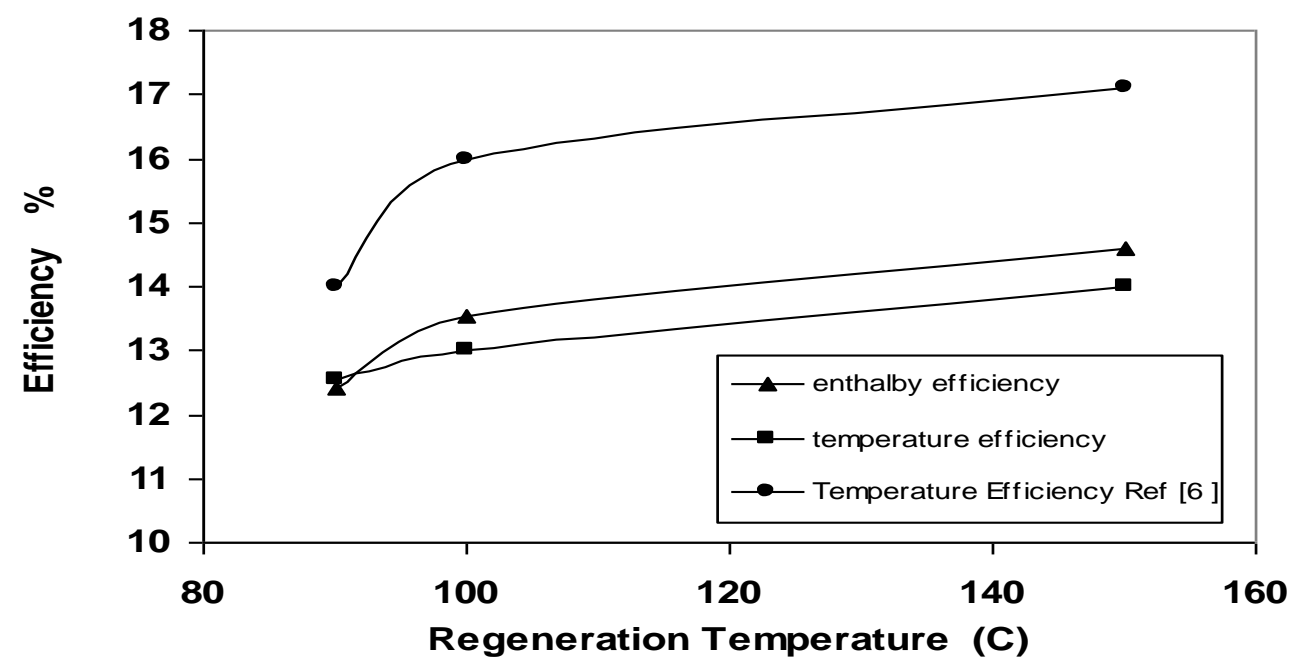

(a)

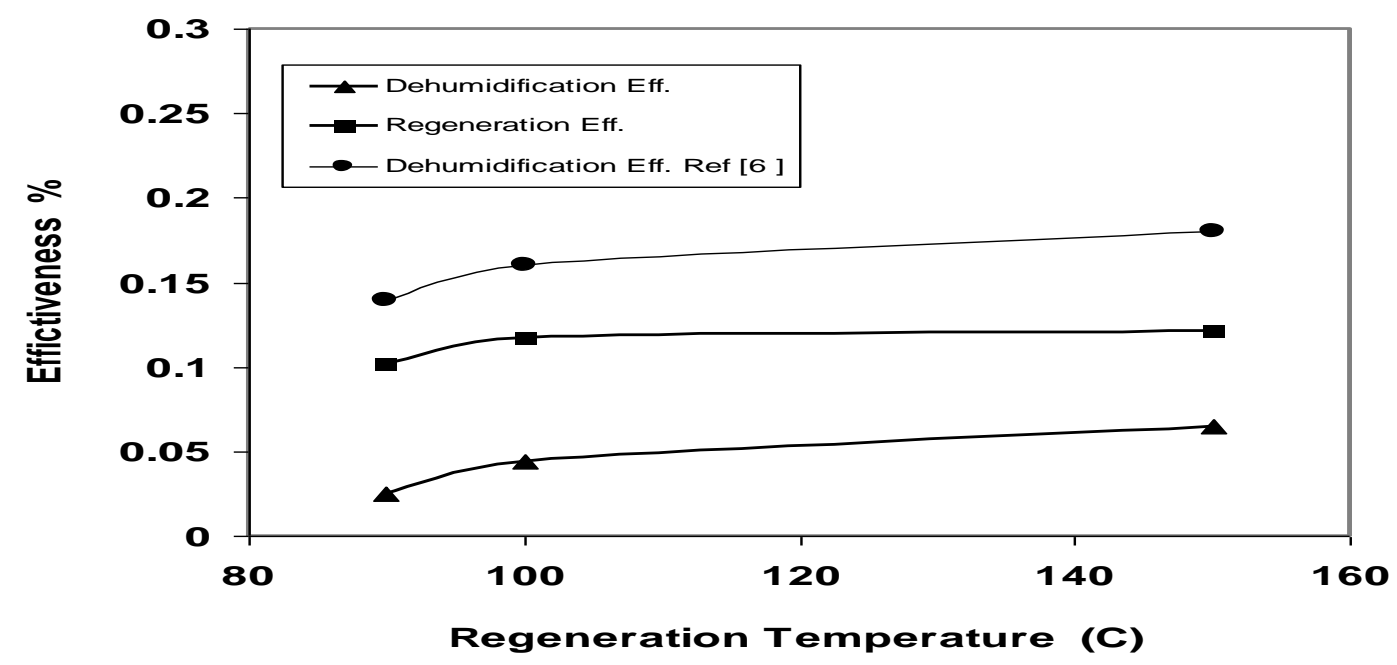

(b)

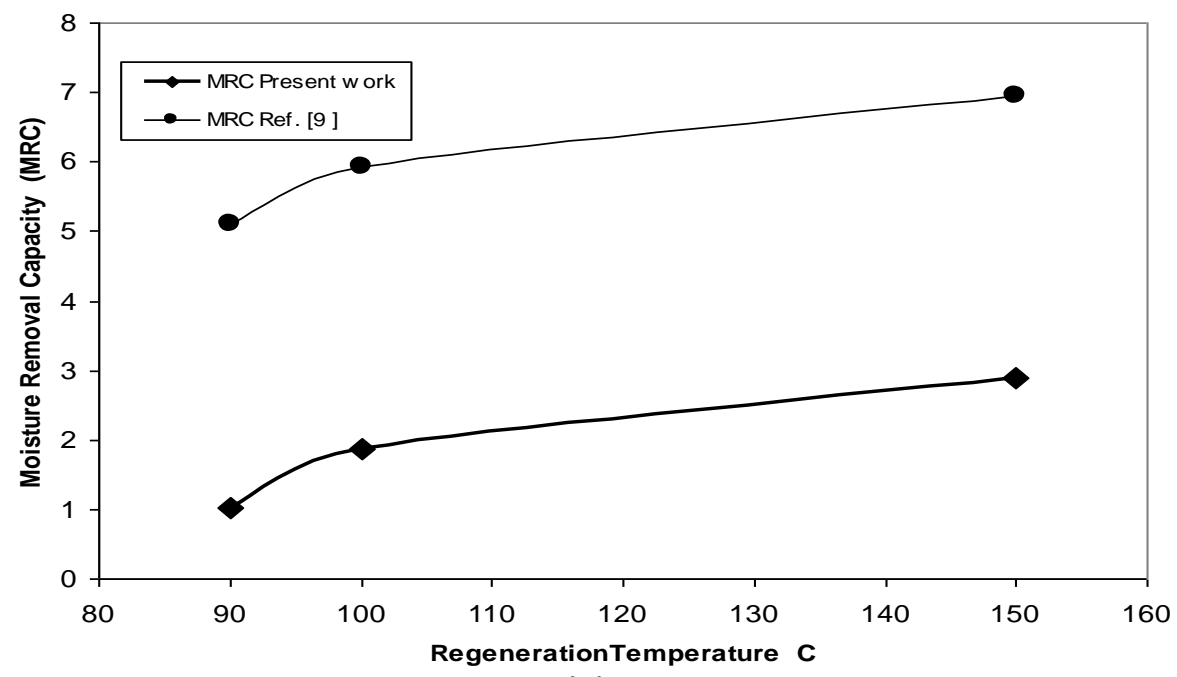

(c) 


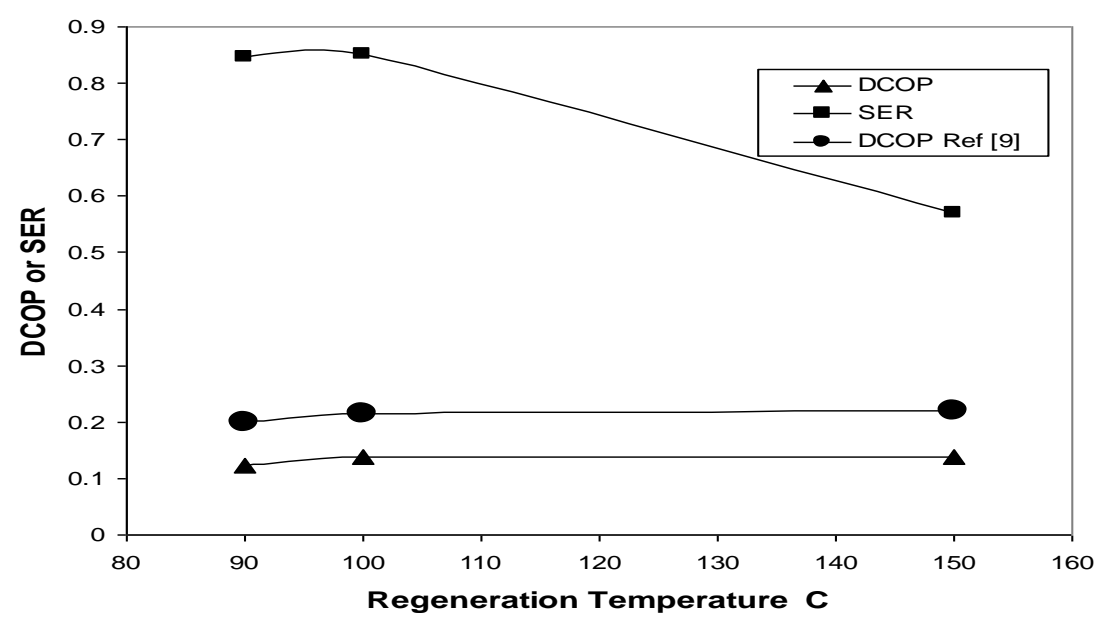

(d)

Fig. 6. Effect of regeneration temperature on (a) enthalpy and temperature efficiencies (b) dehumidification and regeneration effectiveness (c) MRC (d) DCOP and SER.

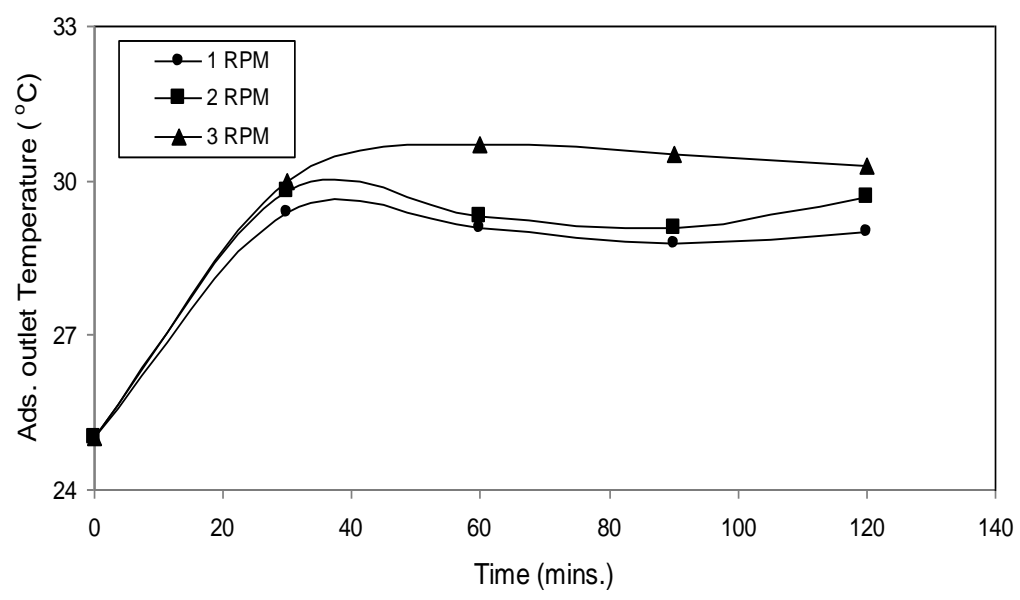

(a)

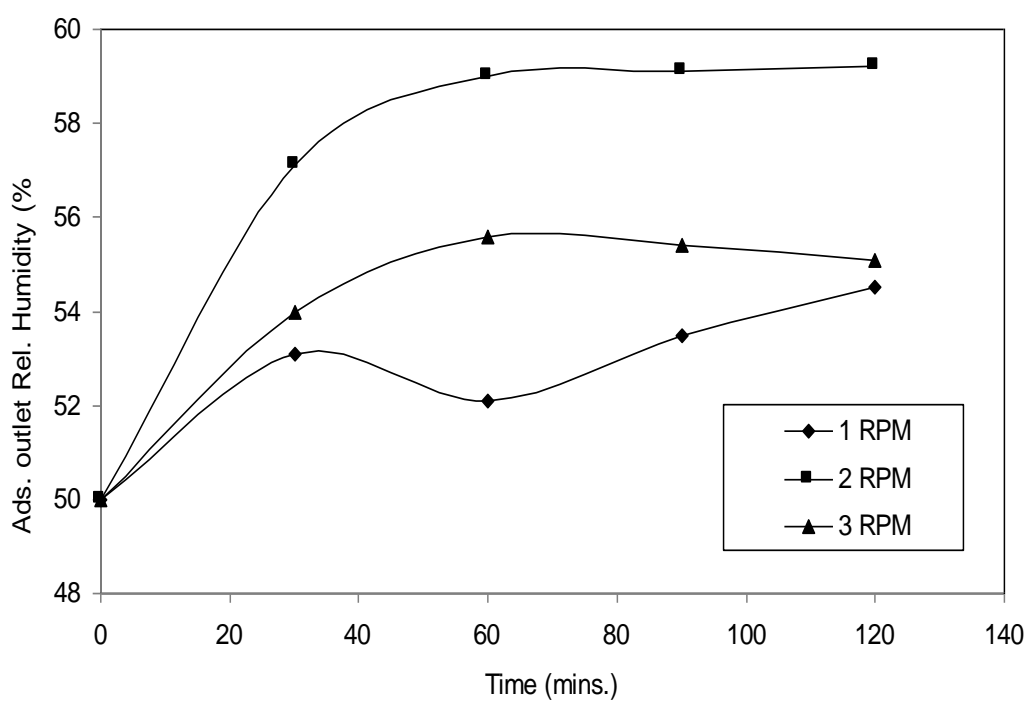

(b)

Fig. 7. The relation between (a) exit ads. temperature (b) exit ads. relative humidity with time at different speed of Desiccant wheel, a quantity of silica gel $(5 \mathrm{~kg})$ and $\mathrm{T}_{\text {Reg }}$ of $150^{\circ} \mathrm{C}$. 


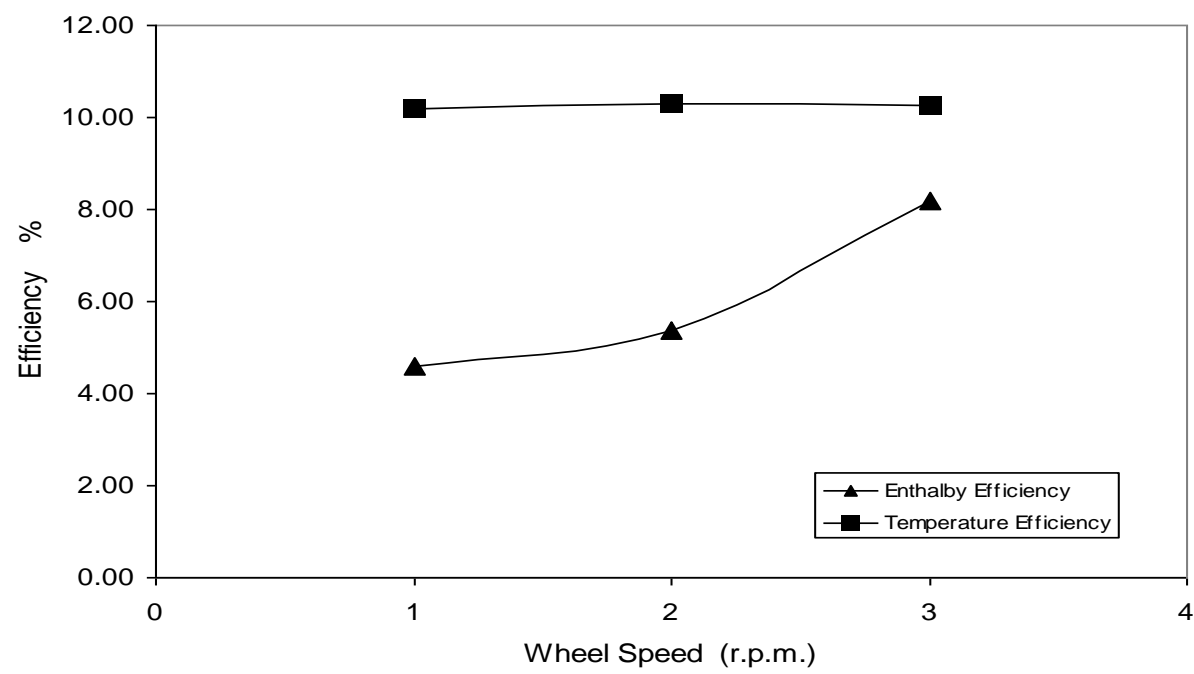

(a)

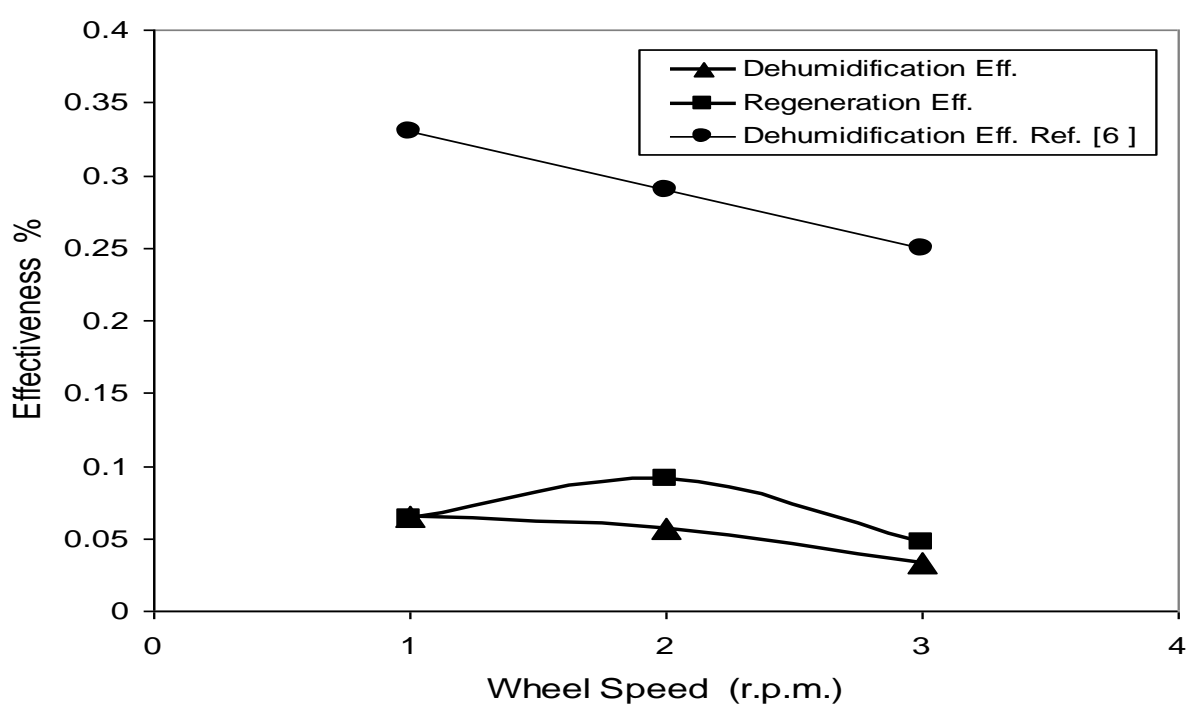

(b)

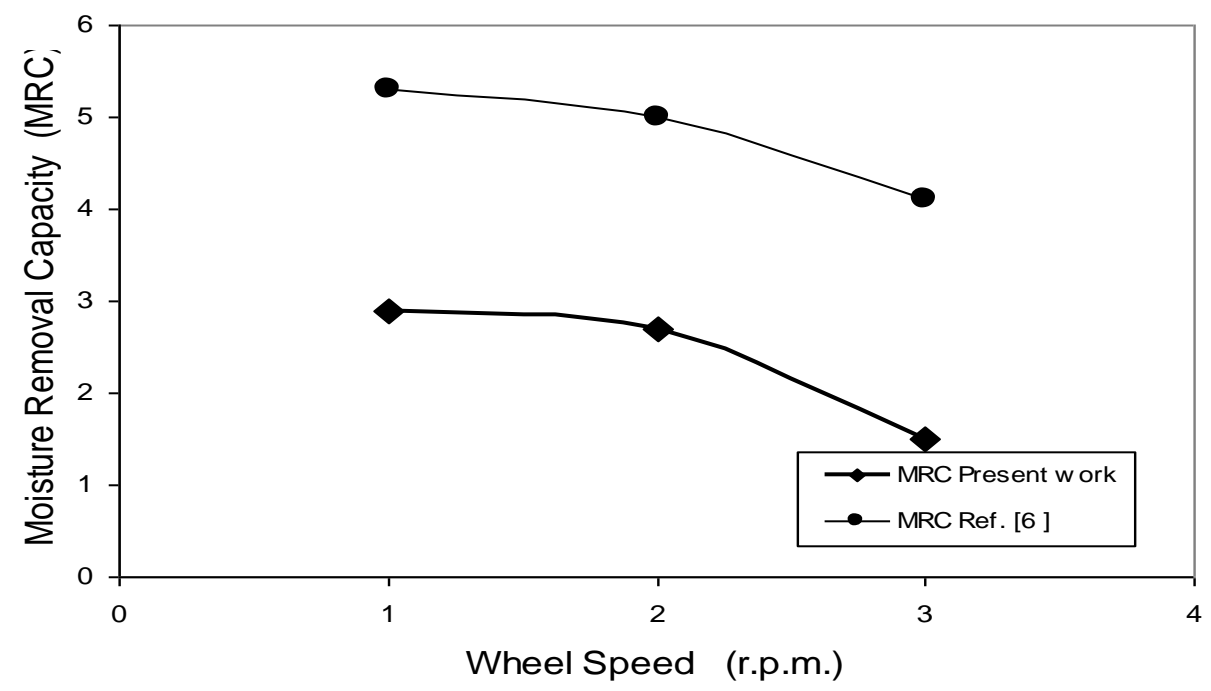

(c) 


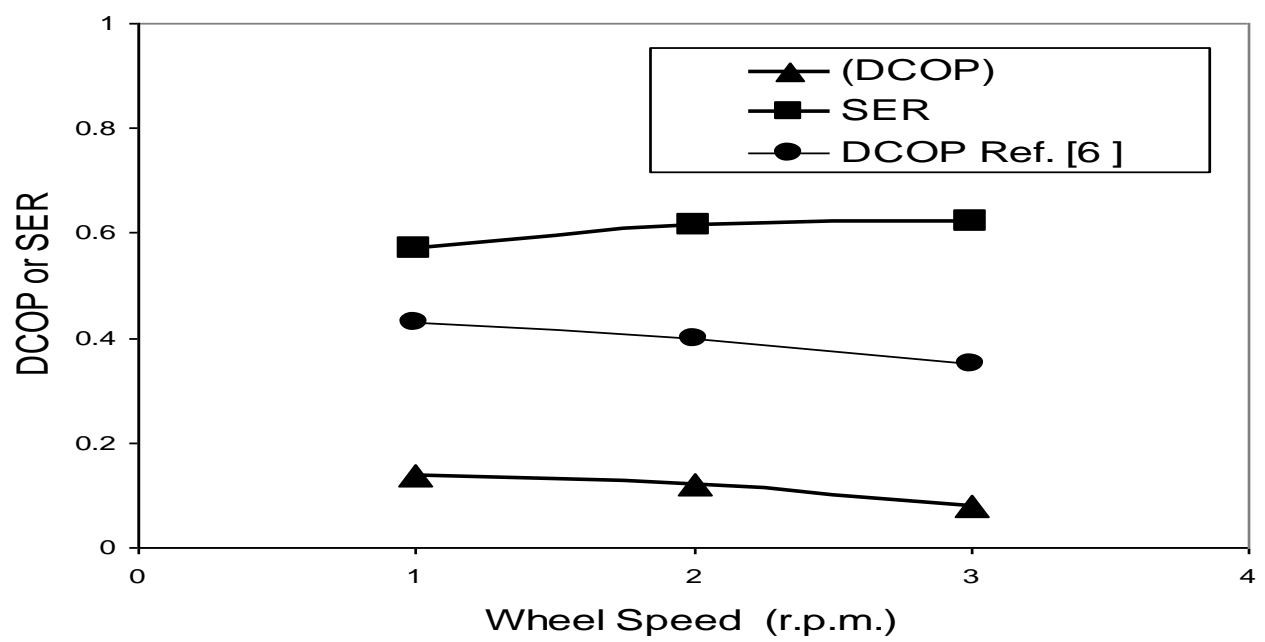

(d)

Fig. 8. Effect of rotation speed on (a) enthalpy and temperature efficiencies (b) dehumidification and regeneration effectiveness (c) MRC (d) DCOP and SER.

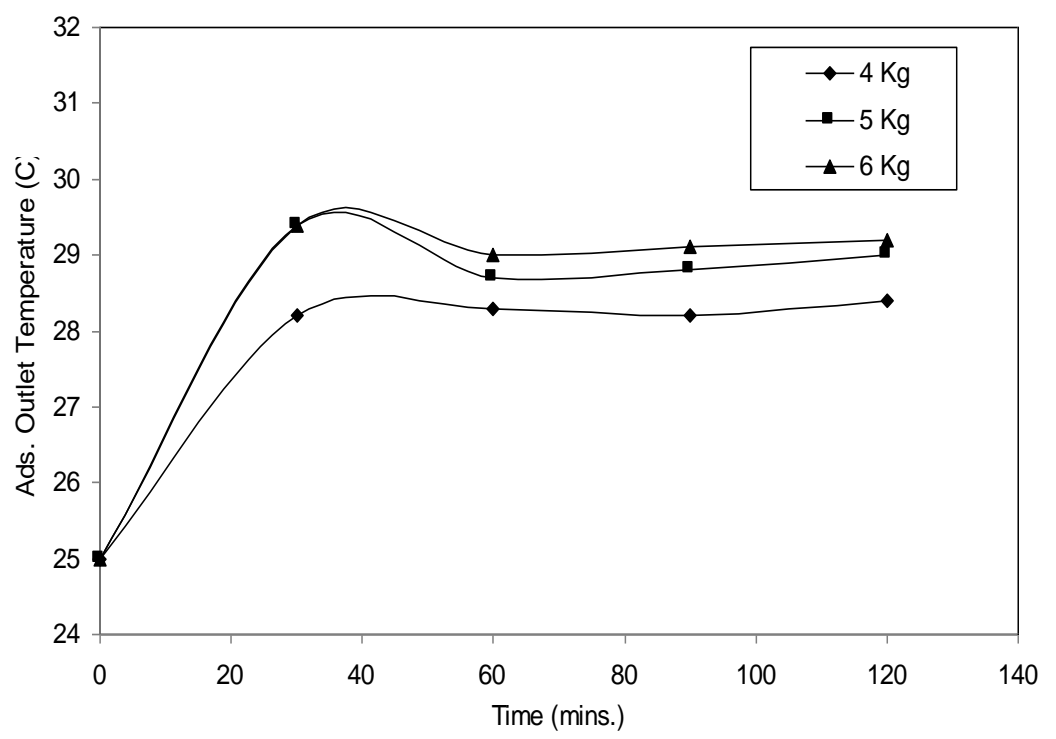

(a)

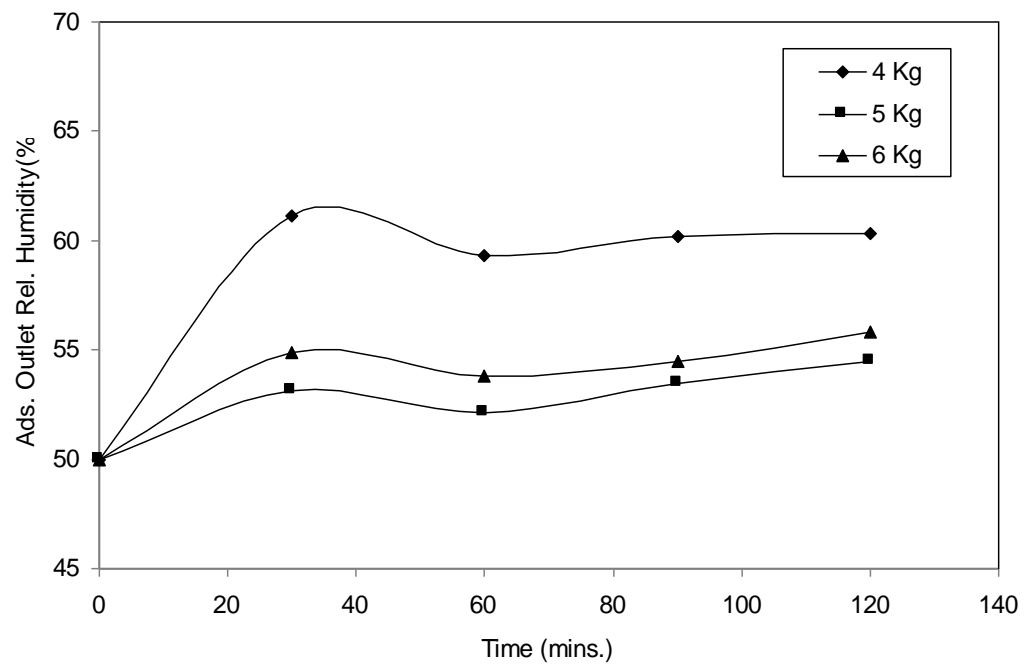

(b)

Fig. 9. The relation between (a) exit ads. temperature (b) exit ads. relative humidity with time at different quantity of silica gel, $\mathrm{T}_{\text {Reg }}$ of $\left(150^{\circ} \mathrm{C}\right)$ and speed of desiccant wheel (1 r.p.m). 


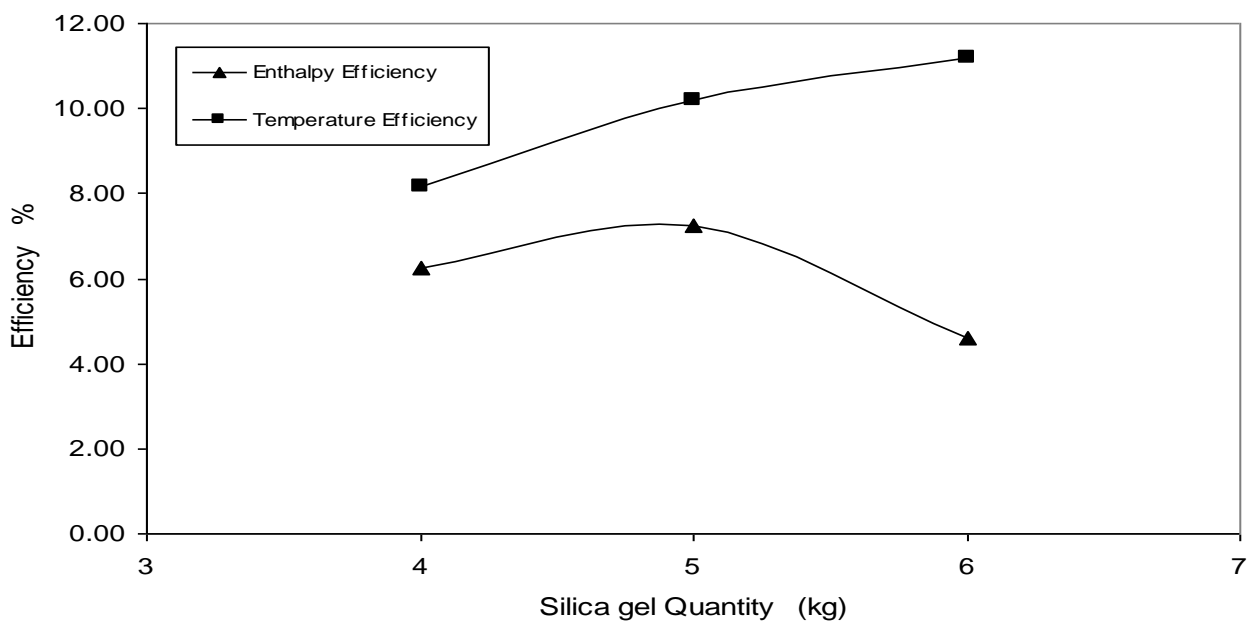

(a)

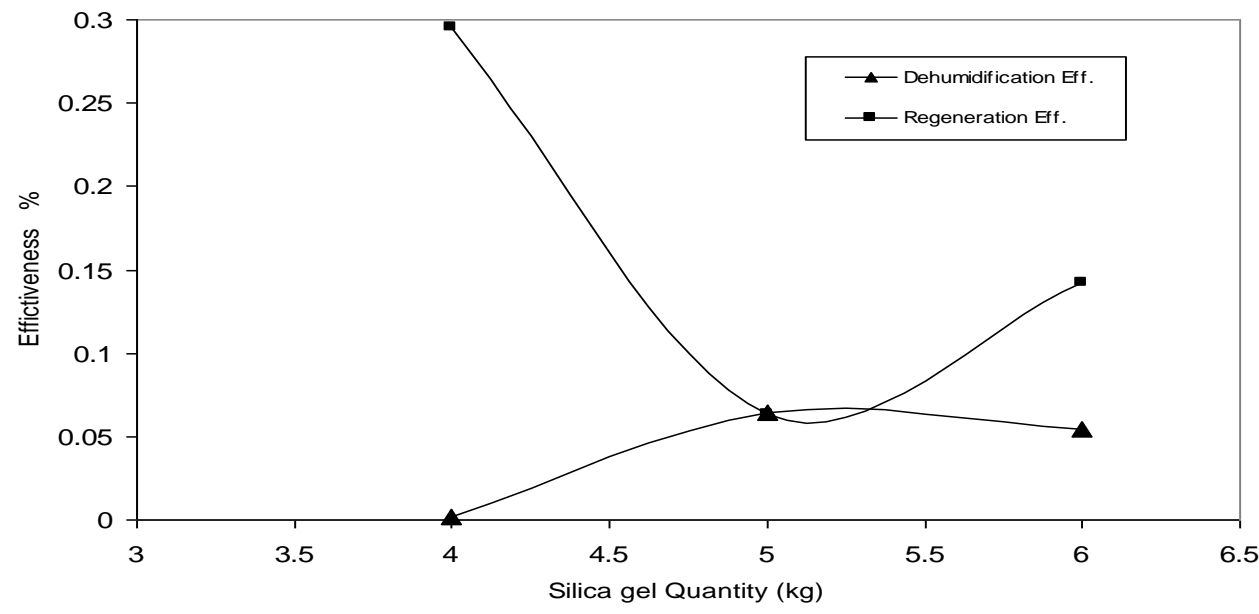

b)

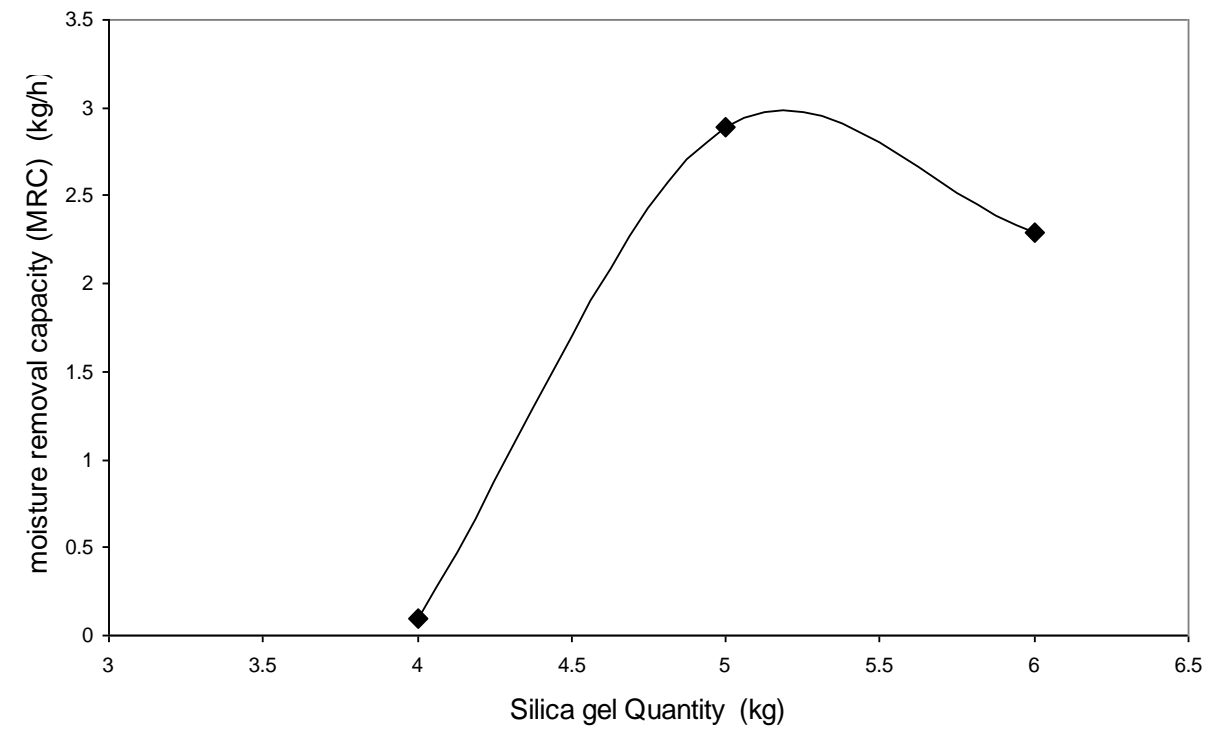

(c) 


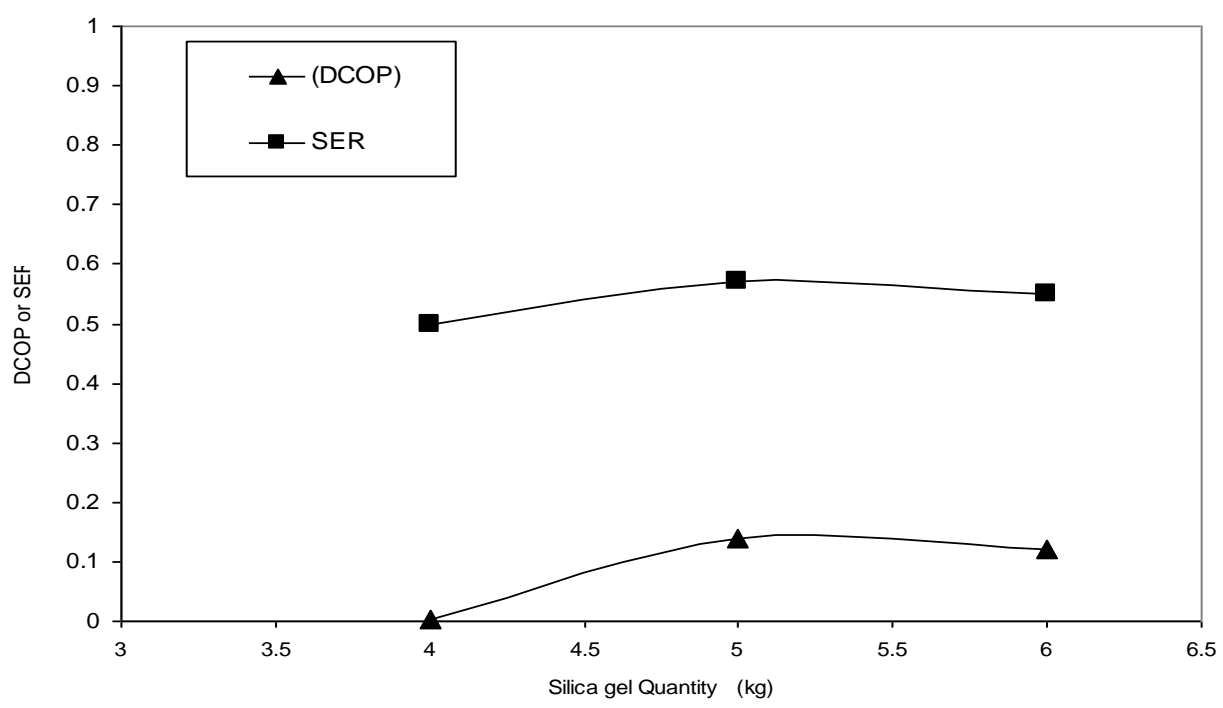

(d)

Fig. 10. Effect of silica gel quantity on (a) enthalpy and temperature efficiencies (b) dehumidification and regeneration effectiveness (c) MRC (d) DCOP and SER.

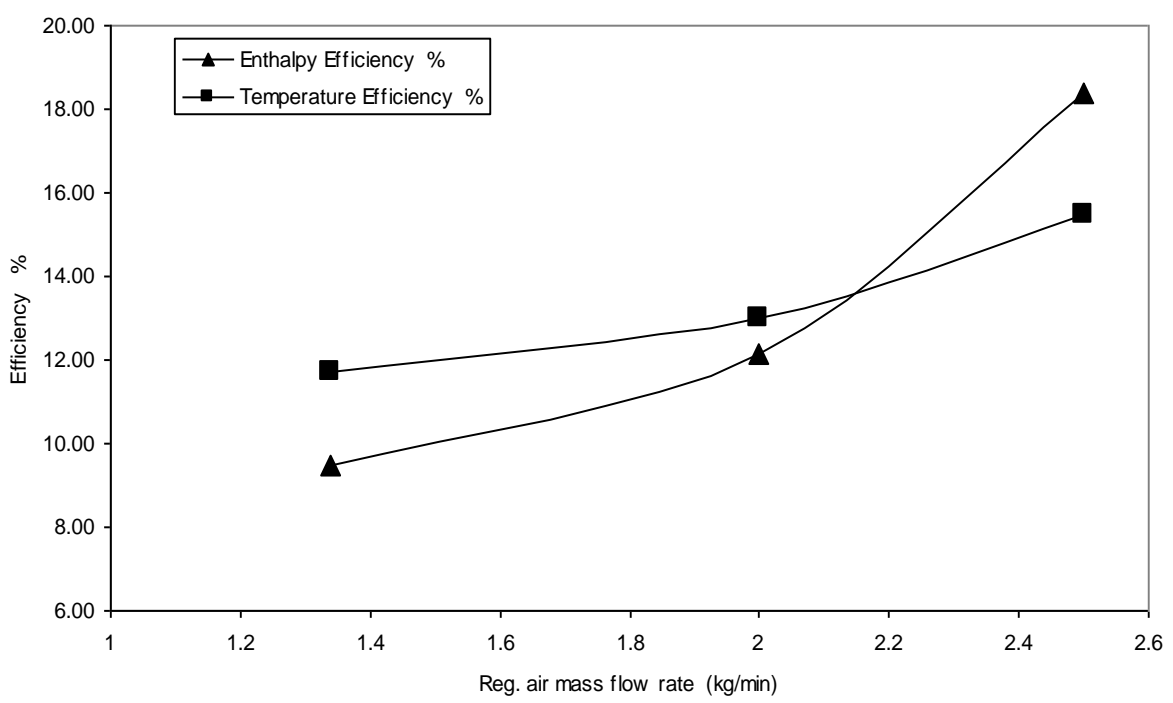

(a)

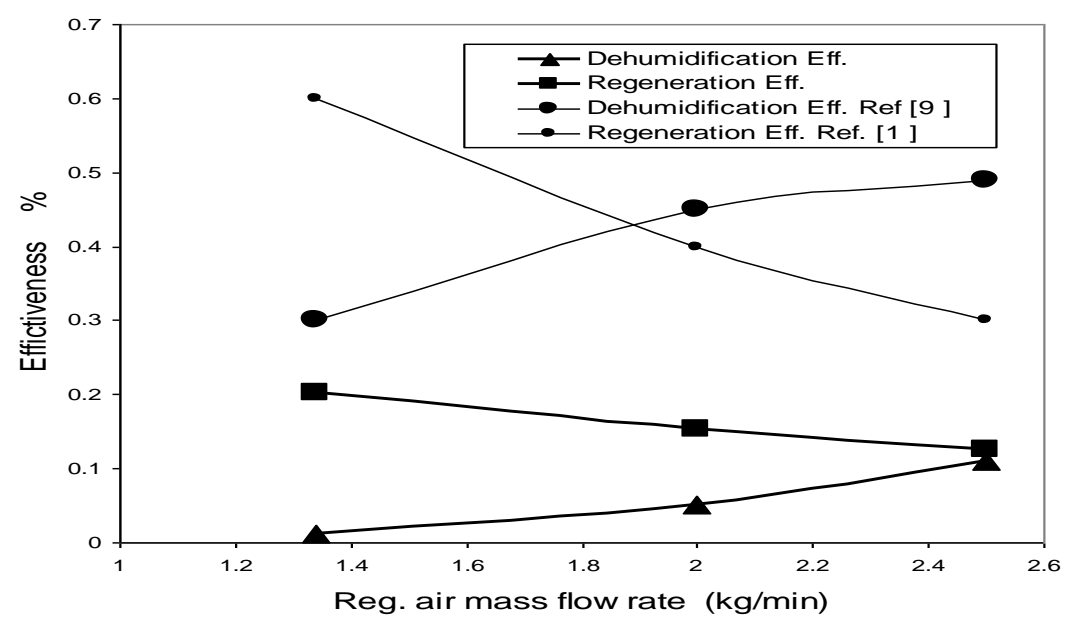

(b) 


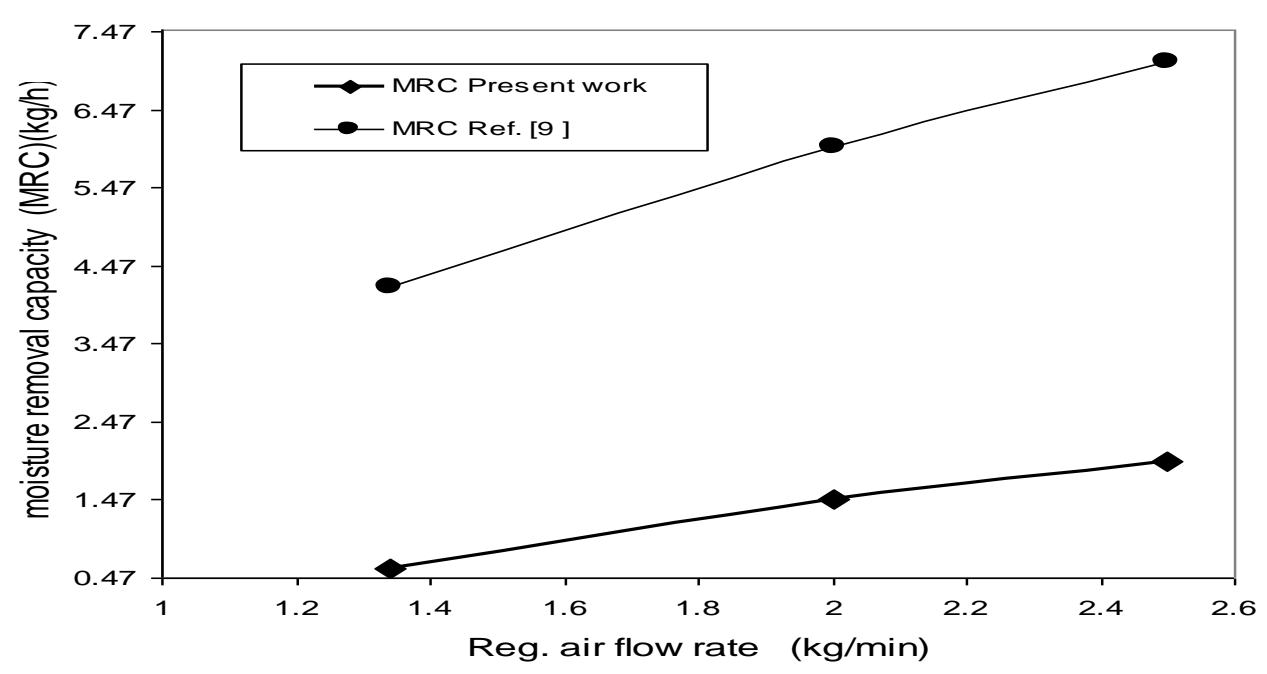

(c)

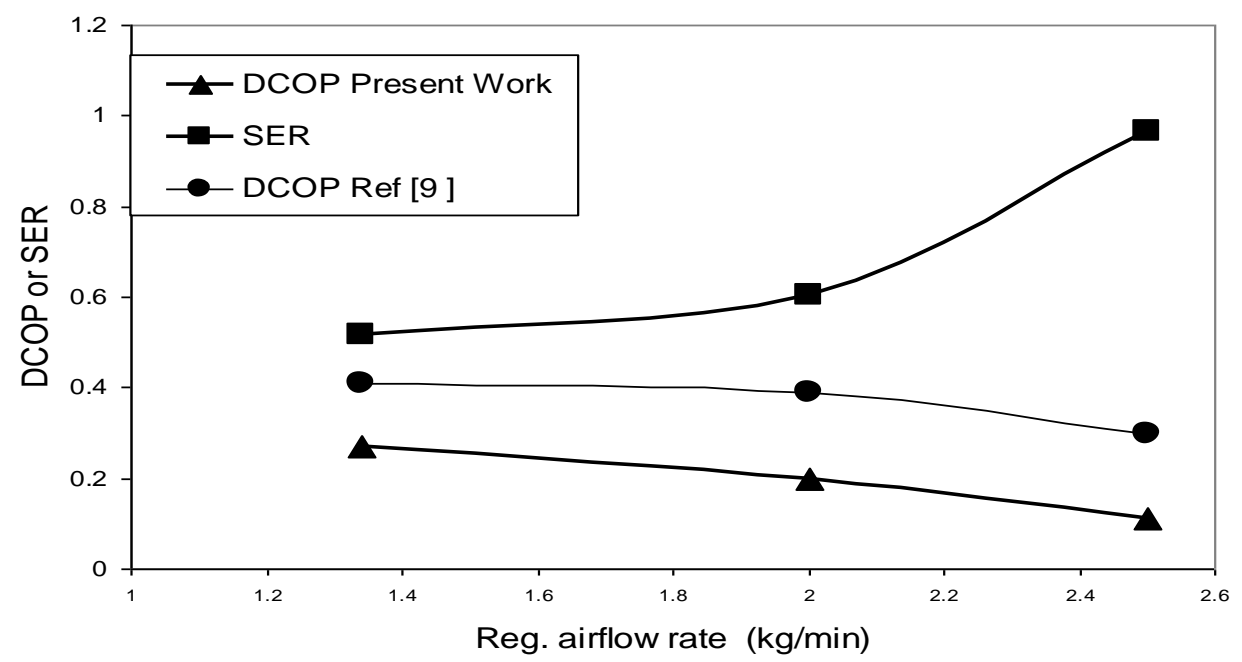

(d)

Fig.11. Effect of regeneration air mass flow rate on (a) enthalpy and temperature efficiencies (b) dehumidification and regeneration effectiveness (c) MRC (d) DCOP and SER.

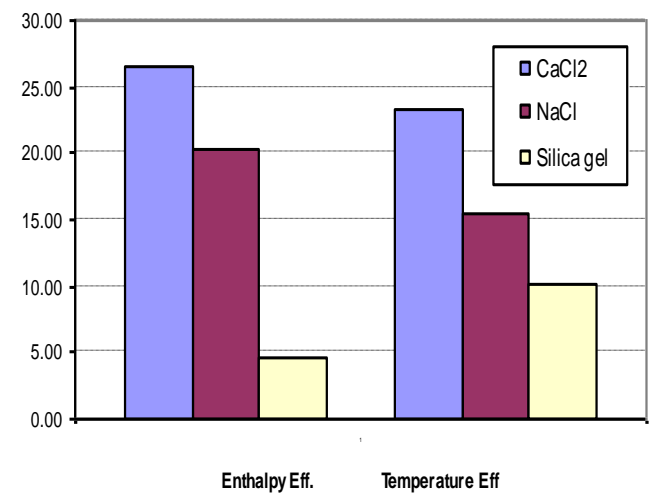

(a)

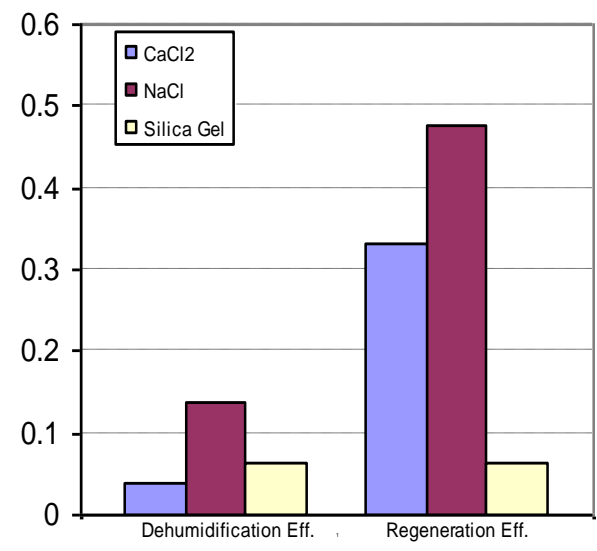

(b) 


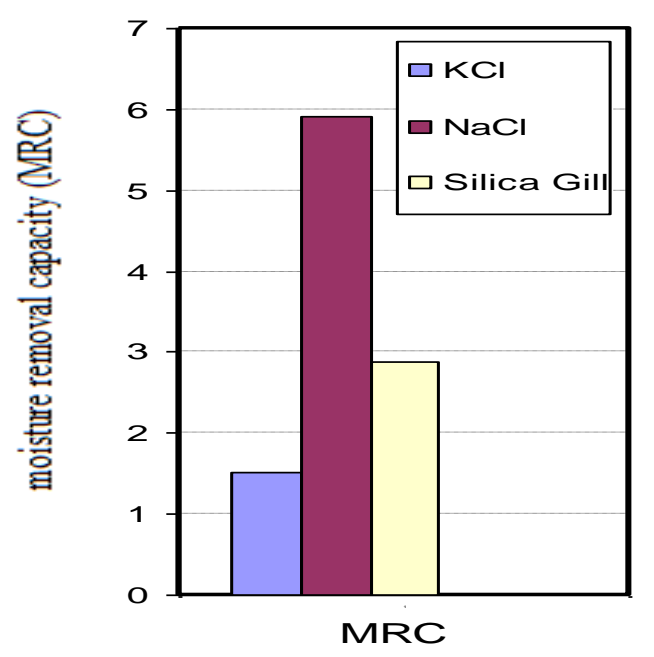

(c)

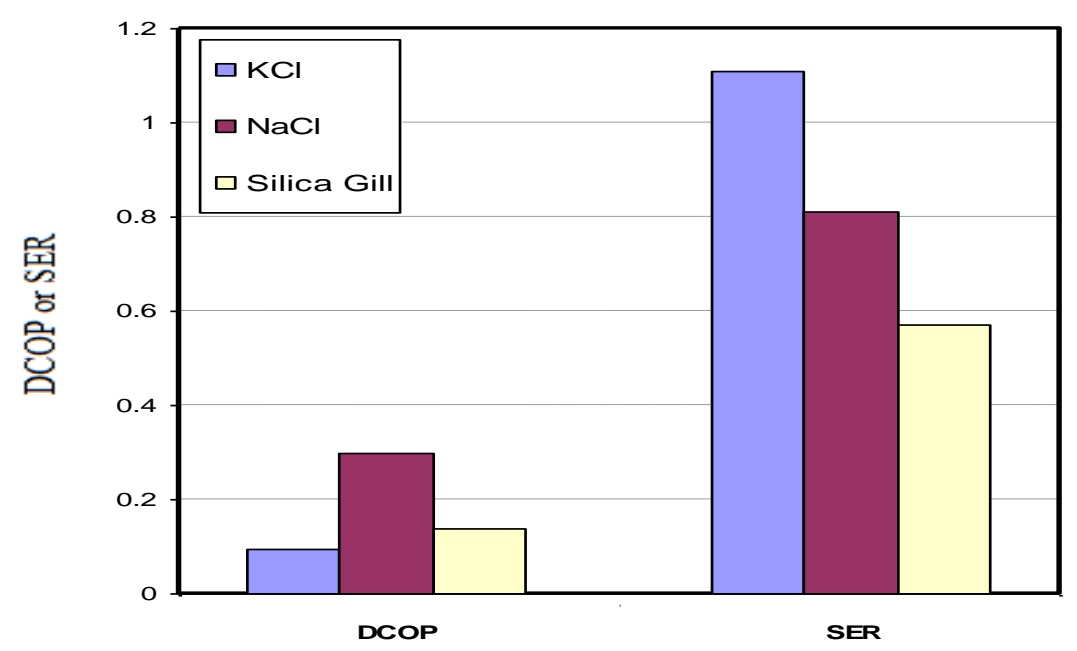

(d)

Fig. 12. Comparison between the best results (a) enthalpy and temperature efficiencies (b) dehumidification and regeneration effectiveness (c) MRC (d) DCOP and SER of Silica gel, calcium chloride and sodium chloride solution. 